\title{
Article
}

\section{Newly qualified Saudi nurses' ability to recognise the deteriorating child in hospital}

\author{
Al-Thubaity, Daifallah, Williamson, Susan, LEAVEY, RALPH and \\ Tume, Lyvonne \\ Available at https://clok.uclan.ac.uk/22498/ \\ Al-Thubaity, Daifallah, Williamson, Susan orcid iconORCID: 0000-0002-9635- \\ 4473, LEAVEY, RALPH and Tume, Lyvonne (2019) Newly qualified Saudi \\ nurses' ability to recognise the deteriorating child in hospital. Nursing In \\ Critical Care, 24 (5). pp. 263-267. ISSN 1362-1017
}

It is advisable to refer to the publisher's version if you intend to cite from the work. http://dx.doi.org/10.1111/nicc. 12356

For more information about UCLan's research in this area go to http://www.uclan.ac.uk/researchgroups/ and search for <name of research Group>.

For information about Research generally at UCLan please go to http://www.uclan.ac.uk/research/

All outputs in CLoK are protected by Intellectual Property Rights law, including Copyright law. Copyright, IPR and Moral Rights for the works on this site are retained by the individual authors and/or other copyright owners. Terms and conditions for use of this material are defined in the policies page.

\section{CLoK}

Central Lancashire online Knowledge www.clok.uclan.ac.uk

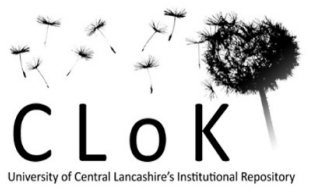


Article title: Newly qualified Saudi nurses' ability to recognise the deteriorating child in hospital

Manuscript type: original research paper

Keywords: Early recognition skills, Monitoring, Deterioration, Paediatrics, Clinical vignettes

Authors details:

Daifallah Al-Thubaity. PhD student, University of Central Lancashire. Preston PR1 2HE. Tel:+44(0)7341580110. Email: dddal-thubaity1@uclan.ac.uk

Dr Susan Williamson. PhD .Senior Research Fellow (University of Central Lancashire )Preston PR1 2HE Tel:+44 (0) 1772892731 Email:

swilliamson2@uclan.ac.uk

Dr Ralph Leavey.PhD. Senior Research Fellow (University of Central Lancashire ) Preston PR1 2HE Tel:+44 (0)1772 895526

Email:rleavey@uclan.ac.uk

Lyvonne Tume. RN Bnurs MSc PGDE PhD Associate Professor in Child Health (University of West of England)Bristol BS16 1DD. Tel:+44 07710412142

Email: lyvonne.tume@uwe.ac.uk 


\section{Background}

It is recognised that nurses' failure to recognise and respond promptly to a deterioration in children's physiological status can result in increased morbidity and mortality.

\section{Aim}

The aim of this study was to explore Saudi-educated newly qualified nurses, working in paediatric wards, ability to recognise children's deterioration.

\section{Methods}

A pilot study was carried out to assess Nurses' responses to three clinical vignettes (deteriorating child, improving child and ambiguous scenarios). The nurses' ability to make a correct identification was captured using a 'Think Aloud' approach and quantified using a visual analogue scale.

\section{Results}

Twenty-seven nurses in two geographical regions in Saudi Arabia participated. Only half the nurses (51.8\%) correctly identified the deteriorating child vignette. Of the ones who could not, $37 \%$ were unsure and $11 \%$ responded incorrectly. No nurses correctly identified all three vignettes, and four nurses (15\%) responded incorrectly to all vignettes.

\section{Relevance to clinical practice}

Newly qualified nurses working in paediatric wards frequently find it difficult to identify the deteriorating child.

\section{Conclusions:}

The recognition of the deteriorating child is complex, and even in non-stressful simulated scenarios using vignettes, many newly qualified nurses working with children failed to recognise clear signs of the deteriorating child. A focused (culturally specific) educational intervention is being developed to target this, taking into account the Saudi nurses' perceived education and training needs.

\section{Introduction}

There is increasing evidence that healthcare professionals are frequently unable to recognise and respond appropriately to the deteriorating child (Sefton et al., 2014: Lambert et al., 2017). In 2009, the National Patient Safety Agency report (NPSA,) 
found adverse events in children ranged from $2 \%$ to almost $11 \%$. The two most common problems were: a failure to recognise the child's severity of illness and poor communication between the professionals involved.

Identifying early deterioration of patients in the hospital is crucial to preventing cardiac and respiratory arrests and improving patient outcomes, and the ability to recognise cues and changes is a necessary and fundamental nursing skill (LevettJones et al. 2010). However, it can be a challenging and complex process involving taking observations and interpreting these in the context of the child's condition and trends over time. There is evidence (Tume 2007; Pearson, 2008; Voepel-Lewis et al. 2013) that paediatric nurses do not always recognise deterioration at an early enough stage in a child's illness to intervene and alert medical staff in order to prevent critical care unit (CCU) admission, cardiopulmonary arrest and even death. This may be even worse in newly qualified nurses due to their lack of experience, and developing skills to adequately detect and respond early to deterioration (Purling and King, 2012; O'Leary, et al., 2014). These findings have resulted in numerous recommendations that health care staff and undergraduate nurse education programmes should be provided with opportunities to practice the complex reasoning skills involved in recognition and responding to patient deterioration (National Patient Safety Agency (NPSA), 2009; Pearson 2008; Berg et al. 2008;

Haines et al., 2005).

Focused educational programmes around deterioration were first developed for adult patients' with the ALERT course (Acute Life-threatening Events Recognition and Treatment) (Smith et al., 2002). This was followed by in children by a focused educational intervention in Australia (Mitchell et al., 2010) and a UK course 
RESPOND (Recognising Signs of Paediatric hOspital iNpatients Deterioration) (Tume, et al., 2014). However, currently no such courses exist in The Kingdom of Saudi Arabia (KSA). The Saudi nurses' undergraduate education is generic and covers both paediatrics and adults. All KSA regions educate nurses based on the same curriculum as dictated by the Saudi Council of Health Specialties (AbuZinadah 2005). This undergraduate paediatric clinical practice preparation includes physiological measurements, disease management and clinical judgement skills. The assumption is, therefore, that all Saudi regions have a similar level of ability upon graduation. Currently, we do not know the level of ability of Saudi trained nurses to recognise the deteriorating child on the paediatric wards. It is, therefore, both pertinent and timely to explore both the ability of Saudi educated paediatric nurses' to recognise clinical deterioration and to understand their perceived educational and training needs in this area. Consequently, the aim of this study was to explore Saudieducated newly qualified nurses, working in paediatric wards, ability to recognise children's deterioration

\section{Methods}

A pilot study was carried out to explore and quantify the nurses' decision-making. We used cognitive interviews using Think Aloud technique (Charters, 2003) to administer three clinical vignettes (Figure 1) to capture the quantitative data related to the nurses' clinical reasoning. The Think Aloud (TA) technique utilises the verbal reports of the nurses' thoughts as they occur to them in their immediate short-term memory to collect data. As a methodology, it has its roots in cognitive psychology (Ericsson, \& Simon, 1980) and was used explore the nurses' decision-making and cognitive processes and gave insights into their real time thinking. There are two protocols used in TA data collecting methods namely concurrent (whilst completing an activity) 
and retrospective (on completion of an activity) which were combined to allow inferences to be made about the cognitive processes during problem solving activities (Young, 2009). During the administration of each of the three vignettes, quantitative data was collected on Visual Analogue Scales (VAS) (McCormack, et al., 1988).

\section{The design of the data collection tools}

The three clinical vignettes used in this study were developed in consultation with an independent expert panel (consisting of a research supervisor, a paediatric advanced nurse practitioner, a paediatric-trained clinical research nurse and a paediatric-trained PICU nurse) for review of their validity as reflecting a 'real life scenario'. The clarity of the wording, and whether each scenario accurately represented the intended scenario (i.e. deteriorating, ambiguous or improving) were evaluated. Minor amendments to the wording and to values/observations were provided, but all the reviewers agreed they clearly represented the three scenarios.

Clinical vignettes have been used since the 1950 s to simulate real events to elicit knowledge and opinions of how people (Gould, 1996) including paediatric nurses (Van Hulle, 2009) respond to hypothetical situations. The Visual Analogue Scales (VAS) (McCormack, et al., 1988; Gould et al., 2001) required the nurses to define their decisions about the scenario and rated their confidence in their decisions. The analogue scale was designed to measure the nurse's ability to recognise the child's clinical condition across a continuum of values that could not otherwise be measured. The scales were constructed to collect ordinal data, on a horizontal line with a scale of 1-10 and fixed at each end by word descriptors. 


\section{Recruitment of participants}

The inclusion criteria were Saudi-educated newly qualified diploma and graduate nurses (defined as less than 12 months since qualification) working in children's hospital wards in two regions of KSA. Both regions have universities that provide undergraduate nursing programmes, which have a common set of paediatric curriculum standards. Region 1 employed 15, and Region 2 employed 19 Saudi educated nurses in the paediatric wards who met the inclusion criteria. The sample was therefore opportunistic and achieved by advertising on the hospital staff notice boards in both regions and gaining permission from the ward manager to talk to staff about the aims and objectives of the research during their regular ward meetings.

\section{Data Collection}

The VAS was administered during the TA cognitive interviews at the same point in time and in the same manner during each vignette scenario with every participant. The nurses were asked to indicate a point on the scale to rate how likely they thought the child was deteriorating. In the first scenario (improving child) the lower range 1-3 was categorised as correct and the higher range of 7-10 as incorrect. This was reversed for the second scenario (deteriorating case). The indeterminate responses to both these the improving and deteriorating scenarios were in the 4-6 range and categorised as such. In the third scenario (ambiguous case), the 4-6 range was categorised as correct and both the lower or higher ranges were categorised as incorrect. The three scenarios were administered consistently for all participants, and in the same order, which was firstly, the improving child, then the deteriorating child and finally the ambiguous clinical scenario. The interviews were audio recorded with the participant's consent and transcribed. 


\section{Analysis}

The participant's responses to the three vignettes (on the VAS) were analysed. Comparison were made between the regions and between graduate and diploma nurses (categorical data) and associations between these variables and outcomes were assessed using Chi-square or Fisher's exact test in IBM SPSS v23. P values $<0.05$ were considered to be significant.

\section{Ethical issues}

This is part of a PhD study and ethical approval was obtained from the University Ethics Committee (STEMH441; 12/4/16), the Saudi Arabian Ministry of Health Affairs and the Hospital Authorities in both regions. Confidentiality was assured by anonymising the data with transcription; the audio files were then deleted. Written informed consent was obtained prior to all the interviews (Long, and Johnson, 2007).

\section{Results}

Twenty-seven newly qualified paediatric nurses from both regions participated between March and April 2016. All were female, between 23-30 years of age and had between 1-12 months experience post qualifying. Fifteen were from region 1(Diploma=7 , BSN=8) and 12 from region 2(Diploma=1, BSN=11). None of the nurses responded correctly to all three clinical vignettes, and four nurses (14\%) from one region responded incorrectly to all three clinical vignettes. In comparison, to the deteriorating child vignette, the correct responses to the improving child vignette and the ambiguous child vignette were worse at $37 \%(n=10)$ and $40 \%(n=11)$ respectively. 
From the vignettes, just over half of the nurses $52 \%(n=14)$ correctly identified the deteriorating child, of the half who failed to correctly identify this, $11 \%(n=3)$ incorrectly identified the deteriorating child as improving and $37 \%(n=10)$ remained unsure of whether the deteriorating child was improving or deteriorating.

There was no significant difference between the two regions regarding recognition of the deteriorating child. In region $1,60 \%$ of nurses correctly identified the deteriorating child versus $42 \%$ in region $2(p=0.119)$. When compared by education level, graduate nurses were more likely to correctly identify the deteriorating child (68\%) than diploma level nurses (13\%) $(p=0.02)$ but this was not significant.

Although one region had more graduate nurses, the other region actually performed better in identifying the deteriorating child.

Overall (for all three vignettes for all nurses with a possible total of 81 responses) $35 / 81(43.3 \%)$ correctly categorised the three vignettes, $23 / 81$ (28.4\%) incorrectly categorised all of them and $28 \%$ of responses were indeterminate (Table 1 ). The greater variation in scores with the ambiguous vignette helped to demonstrate the differences between the two regions, with region 1 nurses providing more correct responses (53.3\%), and region 2 more incorrect responses $(75 \%)(p=0.239)$, but these were not statistically significant.

The majority of the nurses in both regions also failed to correctly identify the improving child vignette 17/27 (63\%). Around half of nurses 13/27 (48.1\%) responded to the improving child vignette with a range of indeterminate decisions, whilst four nurses (15\%) gave incorrect responses. More nurses in Region 1 (47\%) gave correct responses than in Region $2(25 \%)(p=0.026)$. 


\section{Discussion}

This is the first study to examine Saudi-trained nurses working in paediatric wards ability to recognise clinical deterioration. Given the importance of early recognition of deterioration in children is vital in order to improve patient outcomes (Tume, 2007; Pearson, 2008; Wolfe, et al. 2014), it was of concern that $15 \%$ of nurses in this study gave incorrect responses to all the vignettes and that overall around half could not identify the deteriorating child in the vignette. The assumption that all Saudi regions have a similar level of ability at graduation, because of similar curricular was not evident in this study. Despite apparently the same educational input at undergraduate level, nurses working in region 1 outperformed the nurses in region 2. Although it is not clear why this region performed better, it is possible that it is related to the type of clinical experience after qualifying. Surprisingly the region with more graduates performed worse and we cannot explain this.

Overall, graduate nurses appeared to perform better in recognising the deteriorating child in the vignette. Similar results from adult nursing studies has been found (Wheatley, 2006; McDonnell et all, 2015). These studies found that graduate level of education made a difference to the nurses' ability to recognise and respond appropriately to child deterioration (Purling and King 2012; Pantazopoulos et al 2012; Massey, 2017). However, the differences may also be affected by the length of undergraduate education. In the KSA, graduate nurses undertake 5 years of undergraduate education whereas diploma nurses only undertake 2.5 years. This is different to other countries where the standard registered nurse education at degree level is 3 years (AHPRA, 2017; NCSBN, 2012; NMC 2014) and may in part explain our findings. 
Whilst many hospitals internationally have implemented various forms of paediatric early warning systems (PEWS) (Fuijkschot, et al. 2015; Bonafide et al.2012;

Edwards et al., 2010) to improve the recognition of deterioration, they are not in use within KSA at present. Whilst there are a number of disparate PEWS in current use (Lambert et al., 2017) there is an international evaluation underway (Parshuram et al., 2015) and in some countries there is a move to develop a standardised national PEWS tool (Lambert et al., 2017; Clerihew, 2016). Future work may involve implementing a standardised observation chart (with graphical display) for recording vital signs, combined with an escalation algorithm in Saudi Arabia, supported with a focused educational intervention. This may improve the Saudi-trained nurse's clinical decisions around deterioration.

As the Patient Safety Agency report of 2009 claims, and the international perspective (Hillman et al. 2005) confirms, when adverse events in children occur in hospital, the two most common cause were a failure to recognise the severity of the illness and poor communications between professionals. Our findings suggest that these factors are also be a concern for KSA trained paediatric nurses whatever their level of qualification.

There were a number of limitations of our study that warrant consideration. The inferential statistics generated are from small opportunistic (non-probability) samples, which were unevenly distributed between the two regions, and as such, these should be interpreted with caution. Furthermore, despite our best efforts to replicate real life clinical scenarios in the vignettes, the non-clinical nature of the study may not replicate what these nurses would do in real life. The order in which the vignettes 
were introduced may also have impacted our findings. Despite this, we believe that this study has added significantly to the evidence in this field, and is the first to explore this issue in Saudi-trained nurses.

\section{Conclusions}

Our study found that over half of newly qualified nurses working in two regions of KSA could not identify the deteriorating child in a clinical vignette. This confirms others work and reminds us that recognition of deterioration is a complex process, for which newly qualified nurses maybe ill prepared. Even in these non-stressful simulated scenarios, many of the participants working with children failed to recognise clear signs of the deteriorating child. We believe this justifies the development of a culturally specific focussed educational multiprofessional course on recognising children's deterioration for KSA to address the gaps in knowledge around recognising deterioration of children. The use of PEWs may also need to be considered within the KSA.

Impact

a) what is known about the subject

- Paediatric nurses do not always recognise deterioration at an early enough to intervene and prevent a critical care incident.

- Newly qualified nurses lack of experience involved in the complex process of taking observations and interpreting them in the context of the child's condition and trends over time. 
$\square$ Nurse education programmes should be provided with opportunities for nurses to practice the complex reasoning skills involved in recognition and responding to patient deterioration.

b) What this paper contributes.

- This is the first study to examine Saudi-trained paediatric nurses ability to recognise clinical deterioration.

- Over half of newly qualified nurses working in two regions of the Kingdom of Saudi Arabia (KSA) could not identify the deteriorating child.

- The findings justify the development of a culturally specific focussed educational for the KSA to address the gaps in nurses' clinical knowledge 


\section{References}

AbuZinadah, S. (2005). The inception of nursing regulation in Saudi Arabia. Regulation and globalisation. Presented at the 7th International Regulation Conference 20 - 21st May, Tiapei Taiwan

Australian Health Practitioner Regulatory Agency (AHPRA, 2017).Retrieved from http://www.ahpra.gov.au/Education/Approved-Programs-ofStudy.aspx?ref=Nurse\&type=General\&div=Registered\%20Nurse\%20\%28Division\%2 01\%29 Accessed 8 October 2017

Berg, M D., Nadkarni, V M., Zuercher, M., Berg, R A. (2008) In-hospital pediatric cardiac arrest. Pediatric Clinics of North America 55(3), pp 589-604.

Bonafide, C. P., Roberts, K. E., Priestley, M. A., Tibbetts, K. M., Huang, E., Nadkarni, V. M., \& Keren, R. (2012). Development of a pragmatic measure for evaluating and optimizing rapid response systems. Pediatrics, 129(4), pp874-881.

Charters, E. (2003). The use of think-aloud methods in qualitative research an introduction to think-aloud methods. Brock Education Journal, 12(2): pp 68-82.

Clerihew, L., Rowney, D., \& Ker, J. (2016). Simulation in paediatric training. Archives of Disease in Childhood.Education and Practice Edition, 101(1), 8-14. Doi: 10.1136/archdischild-2015-309143 [doi]

Fuijkschot, J., Vernhout, B., Lemson, J., Draaisma, J. M., \& Loeffen, J. L. (2015). Validation of a Paediatric Early Warning Score: first results and implications of usage. European journal of pediatrics, 174(1), 15-21.

Edwards, E. D., Mason, B. W., Oliver, A., \& Powell, C. V. E. (2010). Cohort study to test the predictability of the Melbourne criteria for activation of the medical emergency team. Archives of disease in childhood, archdischild187617.

Ericsson, K. A., \& Simon, H. A. (1980). Verbal reports as data. Psychological review, 87(3), pp215-251.

Gould, D. (1996). Using vignettes to collect data for nursing research studies: how valid are the findings?. Journal of clinical nursing, 5(4): pp 207-212.

Gould, D., Kelly, D., Goldstone, L., \& Gammon, J. (2001). Examining the validity of pressure ulcer risk assessment scales: developing and using illustrated patient simulations to collect the data INFORMATION POINT: Visual Analogue Scale. Journal of clinical nursing, 10(5), pp 697-706.

Haines, C. (2005). Acutely ill children within ward areas-care provision and possible development strategies. Nursing in Critical Care, 10(2), 98-104.

Hillman.K, Chen, J., Cretikos, M., Bellomo, R., Brown, D., Doig, G., Finfer, S., Flabouris, A. and MERIT Study Investigators, (2005). Introduction of the medical 
emergency team (MET) system: a cluster-randomised controlled trial. Lancet, 365(9477), pp.2091-2097.

Lambert, V., Matthews, A., MacDonell, R., \& Fitzsimons, J. (2017). Paediatric early warning systems for detecting and responding to clinical deterioration in children: a systematic review. BMJ open, 7(3), e014497.

Levett-Jones, T., Hoffman, K., Dempsey, J., Jeong, SY-S., Noble, D., Norton, CA., Roche, J., Hickey, N. (2010) The five rights of clinical reasoning: An educational model to enhance nursing students ability to identify and manage clinically at risk patients. Nurse Education Today 30 (6): pp 515- 520.

Long, T., \& Johnson, M. (2007). Research ethics in the real world: issues and solutions for health and social care. Elsevier Health Sciences.

Massey, D., Chaboyer, W., \& Anderson, V. (2017). What factors influence ward nurses' recognition of and response to patient deterioration? An integrative review of the literature. Nursing open, 4(1), 6-23.

McCormack, H. M., David, J. D. L., \& Sheather, S. (1988). Clinical applications of visual analogue scales: a critical review. Psychological medicine, 18(04), pp 10071019.

McDonnell, A., Goodwin, E., Kennedy, F., Hawley, K., Gerrish, K., \& Smith, C. (2015). An evaluation of the implementation of Advanced Nurse Practitioner (ANP) roles in an acute hospital setting. Journal of advanced nursing, 71(4), 789-799.

Mitchell IA, McKay H, Van Leuvan C, Berry R, McCutcheon C, Avard B, Slater N, Neeman T \& Lamberth P A (2010) Prospective controlled trial of the effect of a multifaceted intervention on early recognition and intervention in deteriorating hospital patients. Resuscitation 81 (6): pp 658-666

National Council of State Boards of Nursing, (NCSBN, 2012) . Retrieved from https://www.ncsbn.org/665.htm Accessed 8 October 2017

NPSA. (2009) Review of patient safety for children and young people. London: National Patient Safety Agency, National Reporting and Learning Service.

Nursing and Midwifery Council (NMC, 2014) .Retrieved from https://www.nmc.org.uk/standards/additional-standards/standards-forcompetencefor-registered-nurses/ Accessed 7 October 2017

O'Leary, F., McGarvey, K., Christoff, A., Major, J., Lockie, F., Chayen, G., Wharton, S. (2014). Identifying incidents of suboptimal care during paediatric emergencies-an observational study utilising in situ and simulation centre scenarios. Resuscitation, 85(3): pp 431-436.

Pantazopoulos, I., Tsoni, A., Kouskouni, E., Papadimitriou, L., Johnson, E. O., \& Xanthos, T. (2012). Factors influencing nurses' decisions to activate medical emergency teams. Journal of clinical nursing, 21(17-18), 2668-2678. 
Parshuram, C. S., Dryden-Palmer, K., Farrell, C., Gottesman, R., Gray, M., Hutchison, J. S., \& Nadkarni, V. (2015). Evaluating processes of care and outcomes of children in hospital (EPOCH): study protocol for a randomized controlled trial.

Trials, 16(1), 1.

Pearson, G. ed. (2008). Why Children Die: A Pilot Study 2006. London: Confidential Enquiry into Maternal and Child Health (CEMACH).

Purling, A., and King, L. (2012). A literature review: Graduate nurses' preparedness for recognising and responding to the deteriorating patient. Journal of Clinical Nursing, 21(23): pp 3451-3465 15p. doi:10.1111/j.1365-2702.2012.04348.x

Sefton, G.; Lane, S.; Carrol, E. D. (2014) Performance of Individual Predictors of Deterioration Used in a Paediatric Early Warning Score. Pediatric Critical Care Medicine. 15(4): pp 29-30

Smith G, Osgood V, Crane S. (2002).ALERT Course Development Group ALERT a multiprofessional training course in the care of the acutely ill adult patient.

Resuscitation; 52: pp281-286.

Tume, L. (2007) The deterioration of children in ward areas in a specialist children's hospital. Nursing in critical care, 12(1), pp12-19.

Tume, L. N., Sefton, G., Arrowsmith, P. (2014). Teaching paediatric ward teams to recognise and manage the deteriorating child. Nursing in Critical Care, 19(4): pp196203 8p. doi:10.1111/nicc.12050

Van Hulle Vincent, C., \& Gaddy, E. J. (2009). Pediatric nurses' thinking in response to vignettes on administering analgesics. Research in nursing \& health, 32(5), 530539.

Voepel-Lewis, T., Pechlavanidis, E., Burke, C., \& Talsma, A. N. (2013). Nursing surveillance moderates the relationship between staffing levels and pediatric postoperative serious adverse events: A nested case-control study. International journal of nursing studies. 50 (7): pp 905-913.

Wheatley, I. (2006). The nursing practice of taking level 1 patient observations. Intensive and Critical Care Nursing, 22(2), 115-121.

Wolfe, A. Macfarlane, A. Donkin, M. Marmot, and R. Viner. (2014) why children die: death in infants, children and young people in the UK. London: Royal College of Paediatrics and Child Health.

Young, K. A. (2009). Direct from the source: the value of think-aloud data in understanding learning. The Journal of Educational Enquiry, 6(1): pp 19-33 Figure 1. Clinical Vignettes: Improving, Deteriorating and Ambiguous (neither improving nor deteriorating) 


\section{Vignette 1: Improving scenario}

A 3/12 old boy was admitted to your children's ward after one day history of fever, poor feeding and respiratory symptoms with a diagnosis of suspected bronchiolitis. You are looking after him the day after he was admitted and after doing his observations you find:

HR 150 bpm

Spo2 92\% on $21 /$ min oxygen

RR 45 with mild subcostal recession Temp $37.6^{\circ} \mathrm{C} \quad$ BP: $70 / 50 \mathrm{mmHg}$

AVPU: awake and irritable at times

The mother is present and says, "I think he is looking a bit better "

\section{Vignette 2: Deteriorating scenario}

You are caring for a 14-year-old boy with a history of asthma who has been admitted onto your ward 4 hours ago.

He was admitted because of a sudden onset of shortness of breath at school, which did not resolve with the use of his asthma pump.

Nebulized salbutamol and oral corticosteroids were started in the emergency

department.

You do his observations and they are:

Respiratory rate 48 , with some expiratory wheeze present but his chest is

actually very quiet. His father is with him and is very worried. SpO2 of $87 \%$ on

$40 \%$ oxygen via a facemask

HR120 bpm TEMP $37.5^{\circ} \mathrm{C} \quad$ BP120/80 mmHg

Blood gas results done 4 hours ago in ED were $\mathrm{pH}=7.5, \mathrm{PaCO} 2=30 \mathrm{mmHg}$ and $\mathrm{PaO} 2=65 \mathrm{mmHg}$

\section{Vignette 3: Ambiguous scenario}

In the children's surgical ward, you are looking after a 3-year-old girl one day after an appendectomy. The appendix was ruptured when they got into theatre and she has been started on IV antibiotics post-operatively. When you go to do her observations, her mother says she seems worse and is irritable and crying.

Temp $=38.0{ }^{\circ} \mathrm{C}$

$\mathrm{HR}=120 \mathrm{bpm}$

$\mathrm{RR}=35 \mathrm{Spo} 2 \mathrm{98 \%}$ on room air

$\mathrm{BP}=105 / 60 \mathrm{mmHg}$

\section{Questions:}

Tell me what you think about this child's condition?

Are you worried he is deteriorating or at risk of deteriorating?

On a scale of 1-10, how likely do you think he is to deteriorate and require ICU admission (10 very likely 1 not likely at all)

Not likely Very likely

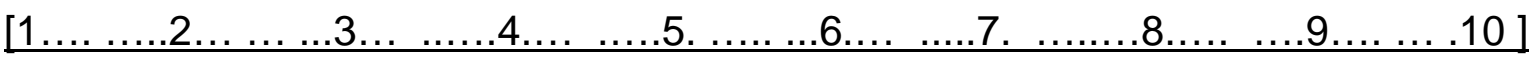

Is there anything else you want to know?

What is your plan what will you do for this child?

Abbreviations: HR Heart rate;Spo2 Saturation of peripheral oxygen ;RR Respiration rate;Temp Temperature; BP Blood pressure; AVPU Alert Verbal stimuli Pain stimuli Unresponsive; ED emergency department; Paco2 partial pressure of carbon dioxide in blood; Pao2 partial pressure of oxygen in arterial blood; IV intra venous; 
Table 1: All nurses responses to the vignette across both regions

\begin{tabular}{|l|c|c|c|c|}
\hline $\begin{array}{l}\text { Responses to } \\
\text { Vignette } \\
\text { Scenarios: }\end{array}$ & $\begin{array}{c}\text { Correct } \\
\text { Responses }\end{array}$ & $\begin{array}{c}\text { Indeterminate } \\
\text { Responses }\end{array}$ & $\begin{array}{c}\text { Incorrect } \\
\text { Responses }\end{array}$ & $\begin{array}{c}\text { Total } \\
\text { possible } \\
\text { responses } \\
\text { to vignettes }\end{array}$ \\
\hline $\begin{array}{l}\text { Vignette 1: } \\
\text { Improving } \\
\text { Scenario }\end{array}$ & $10(37.1 \%)$ & $13(48.1 \%)$ & $4(14.8 \%)$ & 27 \\
\hline $\begin{array}{l}\text { Vignette 2: } \\
\text { Deteriorating } \\
\text { Scenario }\end{array}$ & $14(51.8 \%)$ & $10(37.1 \%)$ & $3(11.1 \%)$ & 27 \\
\hline $\begin{array}{l}\text { Vignette 3: } \\
\text { Ambiguous } \\
\text { Scenario }\end{array}$ & $11(40.7 \%)$ & $0.0 \%$ & $16(59.3 \%)$ & 27 \\
\hline $\begin{array}{l}\text { Total } \\
\text { responses of } \\
\text { all nurses } \\
\text { across both } \\
\text { region }\end{array}$ & $\mathbf{n = 3 5 ( 4 3 . 2 \% )}$ & $\mathbf{N = 2 3 ( 2 8 . 4 \% )}$ & $\mathbf{N = 2 3 ( 2 8 . 4 \% )}$ & $\mathbf{8 1}$ \\
\hline
\end{tabular}

